See discussions, stats, and author profiles for this publication at: https://www.researchgate.net/publication/338838851

\title{
Service Robots in the Hospitality Industry: An Exploratory Literature Review
}

Chapter · January 2020

DOI: 10.1007/978-3-030-38724-2_13

5 authors, including:

$$
\text { Ana Rosete }
$$

University of Aveiro

2 PUBLICATIONS 6 CITATIONS

$$
\text { SEE PROFILE }
$$

(A) Juliana Salvadorinho

University of Aveiro

8 PUBLICATIONS 6 CITATIONS

SEE PROFILE
READS

3,414

Barbara Soares

University of Aveiro

3 PUBliCATIONS 6 CITATIONS

SEE PROFILE

João Carlos Gonçalves dos Reis

Universidade Lusófona de Humanidades e Tecnologias 56 PUBLICATIONS 216 CITATIONS

SEE PROFILE

Some of the authors of this publication are also working on these related projects:

ActYouth EU: From Theory to Action - ActYouth EU View project

Social Entrepreneurship Suppor Europe - SES-EU View project 


\title{
Service Robots in the Hospitality Industry: An Exploratory Literature Review
}

\author{
Ana Rosete, Barbara Soares, Juliana Salvadorinho, João Reis ${ }^{(\bowtie)}$, \\ and Marlene Amorim \\ Department of Economics, Management Industrial Engineering and Tourism, \\ GOVCOPP, Aveiro University, Aveiro, Portugal \\ \{anarosete, barbaramsoares, juliana. salvadorinho, \\ reis.joao,mamorim\}@ua.pt
}

\begin{abstract}
The service sector is changing drastically due the use of robotics and other technologies, such as Artificial Intelligence (AI), Internet of things (IoT), Big Data and Biometrics. Consequently, further research opportunities in the service industry domain are also expected. In light of the above, the purpose of this paper is to explore the potentialities and limitations of service robots in the hospitality industry. To this end, this paper uses a conceptual approach based on a literature review. As a result, we found that in contexts of high customer contact, service robots should be considered to perform standardized tasks due to social/emotional and cognitive/analytical complexity. The hospitality industry is therefore considered closely related to empathic intelligence, as the integration of service robots has not yet reached the desired stage of service delivery. In a seemingly far-fetched context of our reality, organizations will have to decide whether the AI will allow the complete replacement of humans with robots capable of performing the necessary cognitive and emotional tasks. Or investing in balanced capacities by integrating robot-human systems that seems a reasonable option these days.
\end{abstract}

Keywords: Digital transformation $\cdot$ Service robots $\cdot$ Artificial intelligence $\cdot$ Big data $\cdot$ Hospitality industry $\cdot$ Service industry

\section{Introduction}

The emerging domain of service robots encompasses a broad spectrum of advanced technologies and holds the potential to outperform industrial robots in both scope and diversification [1]. Service robots are becoming more common in various activities of daily life [2], such as healthcare [3], mobility [4], and so on. Hospitality services are no exception, as several researchers have been investigating the effects of robotic services on hotel brand experiences [5,6].

It has also been advanced in the literature that service robots and artificial intelligence are being used to provide services to humans, and are gaining increasing attention from hotel and tourism businesses [7]. As a result, we have found that leading companies are combining AI-based technologies with complementary technologies (i.e., robots) with the intent of enhancing or even modernising their service delivery 
systems (SDS's). Despite the growing interest of academics in the service robots' arena, little academic attention has been devoted to this theme, especially in the hospitality frontline services. Recent developments have been labelled by practitioners, who quite dominate the AI field of knowledge [8]. It is worth noting that AI is a classical domain of Computer Science, with significant contributions since the 1960s. The technological phenomenon mention above, especially AI, also deserves the opportunity to be further explored in other fields, such as Business Economics [9, 10], and therefore in the hospitality industry. While we are convinced that current technological developments are being achieved by practitioners, the latter are challenging academics to keep pace.

So, while this article is based on service robot theories, it also tries to shed some light on academia, by reducing the gaps in the literature. In order to conduct scientific research on the shoulders of giants, we selected an article entitled: "Brave new world: service robots in the frontline" by Wirtz et al. [11]. The selected article allowed us to study the service robots in the hospitality industry through the lens of the main dimensions of frontline service delivery by robots, which brought stimulating results. Similar research in the literature focused on scenarios and comparative analysis, notably examples are provided by Bazzano and Lamberti [2], who considered solutions and new implementations that use interfaces to request and give directions (e.g., voice) and/or various embodiments (e.g., physical robot, virtual agents). Our research is different in that it analyses a real-life scenario of a hotel that used service robots in its service systems without any human intervention. This unique case unit allowed us to analyse the positive and negative outcomes of dealing with service robots in frontline services.

We have structured the paper into five sections: it beings with an overview of the topic; followed by a discussion of the most relevant terms and a section that explains the methodological process; we also discuss the results of a case study in the hospitality industry, considering the main dimensions of robot delivery; finally, we explore the implications for practitioners and academics, as well as some suggestions for future research.

\section{Conceptual Background}

Because this paper focus on frontline services in the hospitality industry, it first defines service robots and provides a brief overview of AI; following is a definition of the main dimensions of customer acceptance regarding the introduction of service robots in the frontline services, a categorization of service robots by type of service and it possible roles.

It is generally acceptable that service robots are creating new forms of customer interaction and service experience in the hotel industry [12]. Service robots can be defined as "robotic systems that function as smart, programmable tools, that can sense, think, and to benefit or enable humans" [1, p. 31], which soon covered a broad spectrum of advanced technologies and have the potential to surpass industrial robots in both scope and diversity [1]. Notable example of this is the hospitality industry - the Henn-na hotel in Japan. This hotel, which opened in July 2015, held 80 robots, 
including luggage-carrying arm robots, in-house customer service desk robots, cleaning robots, etc. [13]. Henn-na is known as a fully automated hotel, so guests cannot find any staff [14]. Recent AI advances have also spurred robot development even further, while robots are navigating more complex scenarios due to improved image recognition and processing techniques, and having sophisticated interactions with humans due to increased processing capabilities of natural language [15]. Thus, AI has developed cognitive skills, enhancing human capabilities or strengthening SDS when associated with other technologies, for example robotics.

Wirtz et al. [11] defined three main dimensions of customer acceptance of service robots in the frontline - functional; social-emotional and relational.

Functional dimensions are linked to the customer intention of using new technologies, which depends on the customer cognitive assessment of their utility and ease of use [16]. Regarding the social-emotional dimension [17], it is reported that the presence of robots is best accepted by customers when interlinked with elements such as: (a) perceived humanness, which refers to the indistinguishability of robots from humans [18], examples can be identified as anthropomorphism levels; (b) Social interactivity, where robot design does not have to be necessary as a human to be seen as a social competitor [20], that is, robot behaviour can mimic the human performance; (c) Social presence, identified as a situation where robots are "taking care" and customers feel that they are in the presence of another social being [19]. The relational dimension [20] is closely linked to aspects such as the feeling of trust that robots can convey to customers [21], and the relationship that is characterized as the customer's perception of a pleasant interaction with a service robot, as well as a personal connection between customer and robot [11].

Wirtz et al. [11] also categorize the service robots by service type, namely: task type and service recipient; emotional-social and cognitive complexity; physical task functionality and workload.

Task-type and recipient of service were extensively studied by Lovelock's [22] who distinguished whether a service is directed at people or owned by them and whether these services were tangible or intangible in nature. Emotional-social and cognitive complexity was recently studied by Huang and Rust [24], who defined four level of analytical intelligence: mechanical (i.e. routine and repeated tasks), analytical (i.e. information processing), intuitive (i.e. ability to process complex information), and emphatic intelligence (i.e. ability to read, understand and respond to customers' emotions). According to Wirtz et al. [11], there is a consensus in the literature that the first three levels of AI will develop at a higher level and robots will become dominant delivery mechanisms, but there is considerable debate about whether robots will be effective in providing emotional and social services at a human level, as we will see later in the discussion section. With regard to physical task functionality and service volume, it is expectable that in a near future, service employees will work side by side with robots, which must deal with heavy work or hazardous tasks. 


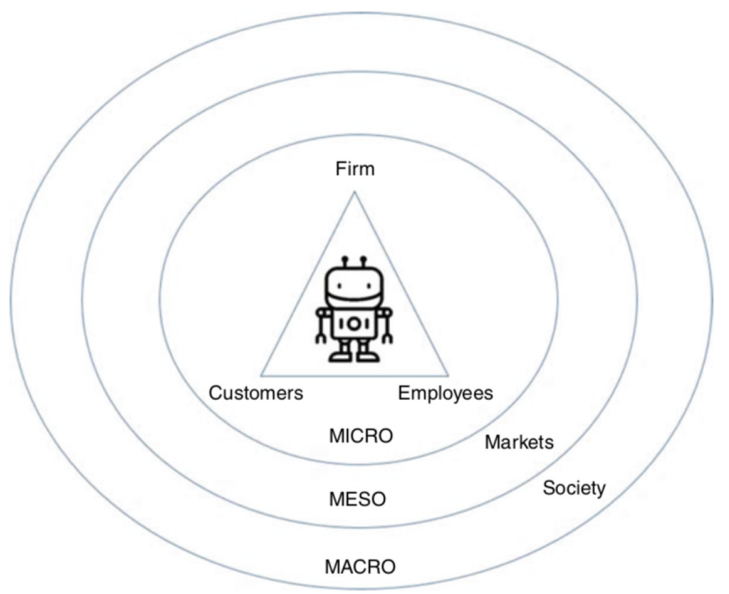

Fig. 1. The impact of service robots on key stakeholders [11]

Finally, Wirtz et al. [11] explore the potential role of service robots, in particular, focus on the impact of service robots on three main levels (Fig. 1): (a) micro level, is identified as the individual customer experience, emphasizing privacy/customer security [24, 25], dehumanization/depersonalization [26] and social deprivation [11]; it is also associated with service training and learning, which is an important ability for employees to provide consistent services; (b) meso level, focus on markets of a particular service and market prices, due to fall in the cost of the service robots, this technology is increasing its viability and range on service industry contexts [27]; (c) and macro level, which refers to societal issues related to employment [23] and inequality [28] within and across societies [11]. All three of these levels will be useful for our analysis.

\section{Methodology}

This article follows a qualitative analysis of samples retrieved from Scopus.com, which has been used as a bibliographic database of peer-reviewed literature. Selecting this database is justified by Scopus's ability to provide a coverage of articles, as it indexes a broad range of AI journals when compared to other known databases, such as Web of Science from Thomson Reuters [8]. A truly comprehensive approach would lead us to select more than one digital repository, however, given that our priority is transparency and easy reproduction of results, this choice may be acceptable when comparing the pros and cons [29].

The data search was conducted on March $8^{\text {th }}, 2019$, and we started with the inclusion criteria using "service robots" in topic (article title, abstract and keywords), and "Henn-na" in all search fields (Table 1). 
Table 1. Literature review process

\begin{tabular}{l|l|l|l|l}
\hline Scopus database & \multicolumn{5}{l|}{} \\
\hline Selected keywords & "Service robots" & \multicolumn{3}{l}{ "Henn-na" } \\
\hline Search & Title-abstract-keywords & 4,048 & All fields & 19 \\
\hline Language & English & 3,848 & English & 17 \\
\hline Source type & Journals & 1,049 & & \\
\hline Document type & Articles & 935 & & \\
\hline Years & $2019-2017$ & 242 & & \\
\hline
\end{tabular}

To cover a large number of international publication, we have selected journal articles in English language; furthermore, to avoid misinterpretations, articles in other languages were excluded. In addition, to ensure quality, the study included indexed scientific research from over a three-year period covering the current state-of-the-art. Regarding the second keyword, i.e. Henn-na, we did not apply any filters other than the language, as it would further restrict the few results obtained. In order to finding corroboration, we included additional articles, especially conference proceedings, as it was difficult to find corroboration among researchers. This is therefore a hot topic that, in our understanding, needs to be further explored by scholars.

Regarding the content analysis, the fourth author manually coded the manuscripts, hierarchizing all categories and subcategories in order to identify emerging ideas. To ensure high quality, unbiased review and reliability, the remaining authors independently read and coded the data with a qualitative analysis software package (i.e., NVIVO 11) for the purpose of making adjustments, until redundancies and contradictions were clarified. The software allowed the researchers to handle a large volume of data at relative fast pace to cross-check the first results. The differences identified between manual analysis and software coding were discussed until a consensus was reached among researchers, allowing the results to be refined and, consequently, to find evidence.

The results of this research have been limited due to the methodological options. The first restriction is related to Scopus database as it is constantly being updated with newly peer-reviewed research. Our sample mainly consisted of journal articles based on the assumption that these manuscripts were of better quality due the rigorous revision process, although we recognize that eventually some relevant articles from other sources have been left behind. A related restriction is associated to the selected keywords; as another similar keyword might yield different results. Recognizing the limitations mentioned, we still believe the literature review has its value, as it synthesizes the existing body knowledge in few pages and provides an exploratory overview of the phenomenon. Last but not least, we have just reviewed a human-robot hotel due to space limitations of the paper, although we believe that the results are similar to equivalent hotels, so more research is needed. 


\section{Findings and Discussion}

\subsection{Is the Hospitality Industry Moving to Full Range Automation?}

Despite valuable research from the past, there are relatively few studies on guest rating studies on the hotel brand experience that compare service delivery by a human staff and/or a robot [5]; therefore, no study to date has examined the performance of frontline service robots through the lens of the key dimensions of frontline service delivered by robot. But, why is this relevant? As some authors argue, "it is likely to have technological capability of delivering service with few or no human is a possibility in the field of hospitality" [30, p. 2] our opinion is that further research is needed in this regard.

The need to deepen the theoretical research is quite obvious, as we find contradictory studies in the literature. For instance, Nakanishi et al. [31] conducted a research to investigate whether humanoid robots engage in heart-warming interaction service in hotels. From Nakanishi et al. [31] customers' impression is that "humanoid robot's potential for heart-warming interaction service enhances the customer's satisfaction of the whole service" (p. 45); at the same time, the authors reinforce the fact that "technology of the human-robot social interaction will hopefully permeate other hospitality services or emotional labour from now on" (p. 52). Although somewhat more sceptical, Osawa et al. [13] do not exclude the aforementioned possibility, and they argue that "although human emotional labour seems difficult to simply replace with robot technologies, there is a possibility that human emotional labour can be replaced in a very complicated way" (p. 223). The sceptical positions, above all, point out that the technological gains of robot services to perform complex social-emotional tasks are still a vision. In that regard, Can and Tung [5] state that "among all levels of hotels, robotic service decreased affective experience, a possible reason for this result is the limitations of current robotic technology as service robots cannot imitate humans to the same extent, in terms of emotions" (p. 466). Consequently, it is common to find in the literature articles that aim to make non-humanoid mobile robots more enjoyable with the intention of imitating human social behaviour [32]. The Henn-na hotel, mentioned earlier, which included in its reception services realistic humanoid robots [33] or anthropomorphic-human like, also required human intervention in its service operations [34]. Accordingly, human-robot interactions (HRI) have attracted considerable attention in the robotic research community [35]. The point is that the Henn-na hotel recently removed more than half of its robotic workforce, as these robots were not advanced enough to perform social activities (e.g. in-room robots failed to answer customer questions) and guests were frustrated [36]. Overall, many Henn-na hotel guest suffered disruption as they were unable to communicate with robots due to language barriers, while another Henn-na guest felt the technology was "not there yet" because it could not help clients where needed [37].

Given the above, Lu et al. [7] suggest that the emotional/hedonic and utilitarian aspects (e.g., performance efficacy) of AI-based technology and service robots are critical determinants of their integration into service delivery. 


\subsection{Service Robots' vs Humans: Semi-automated Systems}

Within the ecosystem framework, we acknowledge other domains in which service robots have been evolved, from one-function automation to intelligent systems of versatile features, sharing the same space and tasks with humans [38]. Lu et al. [7] state that their article sheds light on the hedonic and utilitarian nature of AI technology infusion in hospitality services, as the service industry pioneered the adaptation to new technologies to enhance the user experience. Ivanov et al. [14] have made some progress in this regard as they argued that robotics and AI can become a viable alternative to human employees in travel, tourism and hospitality companies. However, the aforementioned authors believe that not all service processes can and should be automated or performed by robots - "at the end of the day it is the economic efficiency, customer experience, company's competitiveness and other factors that will determine whether the automate and robotise the service delivery process" (p. 1512). Despite the advancements made on AI technologies in the context of hospitality services, scholars have not yet extended sufficient advances in the field of service robots [7]. In addition, we can find some empirical developments on the application of AI-enabled technologies that are not consensual in other SDS's. For instance, Pezzullo's et al. [39] surveyed radiologists who expressed dissatisfaction with AI technologies, feeling frustration that results from erroneous radiology reports were higher compared to traditional transcription services. On the other hand, Gartner et al. [40] found that AI methods and programming-based features increased the hospital's contribution margin.

So what solutions can be considered, in addition to the use of AI-enabled technologies, that can enhance the service robot capabilities in the hospitality industry? In light with Wirtz et al. [11], which mapped the customer needs to robot capabilities, it is quite evident that hospitality, in a first instance, can be conceived as a task of simple analytical-cognitive complexity and high emotional complexity; for this reason, given the limitations presented by robots in a first stage of service, their assignment will tend to be more in favour of humans. Therefore, robot interactions in frontline hospitality services should be considered insufficient because they usually do not meet the dimensions of human-oriented perception, demonstrating high levels of impersonality "these services will by and large continue to be delivered by people" [11, p. 919].

It should be noted that in the hospitality industry, a preponderant part of the service generates emotions relevant to customer satisfaction and, therefore, to service loyalty. Service robots have been used in highly standardized service operations [5], without a high level of interpersonal demand [7, 15], making the service a unique act. However, in order for the service to become highly personalized, providers need to have complex cognitive and emotional social skills (e.g. healthcare services), which are categorized as highly customized services with often uncertain outcomes [11]. Wirtz et al. [11] argues that it seems unlikely that robots possess the social intelligence and communications skills to deal with complex emotional issues. In the light of the above, we understand that frontline hotel services can be considered an experience of cognitive and emotional complexity, let's see if a customer wants to hail a cab, or ask for directions - simple instructions that can be partially resolved by AI; but complex issues, such as mediating service complaints, may require demanding skills from frontline employees who are likely to be more comfortable acting with the help of AI or robot support - that is, 
service delivered by teams of robot and humans. Similarly, Reis et al. [41] argue that companies are adopting strategies to solve complex service failures because frontline employees are playing important roles in performing service recovery activities, while in some cases these employees complement their activities with offline technologies. Tung and Law [42] go further as they uncover unexplored possibilities such as "human operators to be telepresent on screen from copresent robots" (p. 17), which could be a reliable option when dealing with complex service failures that surpasses the capabilities of frontline employees. Special attention to be given to issues related to anthropomorphic-human like - which are critical components to customers' acceptance, particularly hospitality services contexts [15]. Although, Tung and Au [37] findings suggest that experienced discrepancies at the Henn-na hotel between anthropomorphic robots still fails to perform human tasks, resulting in negative guest experience and deterrence against robot services as they are considered "just a gimmick" or marketing ploy. At the end of the line, advances in robotics and AI technologies incorporate broad research opportunities in the hospitality segment, while practitioners are advancing ideas that can inspire academics to find new avenues for research [42, 43].

\subsection{Human-Robot Systems: Micro, Meso and Macro Levels}

The discussion in this section continues to provide information about hospitality services and, consequently, about the customer experience from a micro, meso, and macro perspective (Table 2). The frontline services can be characterized as highly cognitive and social-emotional, so the use of human-robot systems is likely to be considered. In light of the above option, these systems can add the best features of humans and robots.

Overall, the literature considers that frontline employees should provide services that require a high degree of personalization, heterogeneous and strong emotional relation; on the other hand, high consistency services and high analytical-cognitive complexity can be performed by service robots.

Table 2 shows that Henn-na Hotel employees pooled 5 positive $/ 3$ negative items against service robots which have collected 4 positive/4 negative items. This analysis reinforces the reasons why robots in the frontline services were replaced by humans four years after the opening of Henn-na [45].

Micro Level: Henn-na hotel staff has engaged in out-of-box thinking, bringing together creative problem-solving solutions, seeking answers that are tailored to customer needs. For instance, at Henn-na, human work not only provides customers with answers to questions, but employees were required to experience the difficulties visitors may face - robots could not perform these tasks [44]. On the other hand, employee integration is demanding from a training angle, unlike service robots. From customers' perception, employees can provide personalized service, while robots have the ability to deliver consistent, high-performance services. However, front-desk robot's ability to communicate was very limited, especially in the absence of any complementary AI technology. These limitations can cause user frustration and disappointment, especially if guests face the same challenge multiple times; therefore, additional staff training may be required to communicate and explain to guests the type of services that robots may or may not perform [37]. 
Table 2. Human-robot systems: micro, meso and macro levels (Adapted from Wirtz et al. [11])

\begin{tabular}{|c|c|c|c|c|c|c|}
\hline \multicolumn{2}{|c|}{ Frontline services } & \multicolumn{2}{|c|}{ Employees } & \multicolumn{2}{|c|}{ Robots } & \multirow{2}{*}{$\begin{array}{l}\text { Henn-na hotel } \\
\text { Reduced customer } \\
\text { relationship [34] }\end{array}$} \\
\hline Micro & $\begin{array}{l}\text { Employees } \\
\text { training }\end{array}$ & + & $\begin{array}{l}\text { Can engage in } \\
\text { out-of-box } \\
\text { thinking and } \\
\text { creative problem } \\
\text { solving }\end{array}$ & - & $\begin{array}{l}\text { Limited out-of-box } \\
\text { thinking }\end{array}$ & \\
\hline & & - & Need training & + & $\begin{array}{l}\text { Upgradable, system- } \\
\text { wide }\end{array}$ & $\begin{array}{l}\text { At Henn-na hotel, } \\
\text { education is provided } \\
\text { so that any employee } \\
\text { can handle such work } \\
{[44, \text { p. } 242]}\end{array}$ \\
\hline & & + & $\begin{array}{l}\text { Understanding of } \\
\text { their customers }\end{array}$ & - & Pattern recognition & $\begin{array}{l}\text { Employees are } \\
\text { required to sense } \\
\text { difficulties that } \\
\text { visitors may be } \\
\text { facing, and visitors } \\
\text { expect that employees } \\
\text { will try to ascertain } \\
\text { their reactions, the } \\
\text { reception robot } \\
\text { cannot perform such } \\
\text { tasks [44] }\end{array}$ \\
\hline & $\begin{array}{l}\text { Customer } \\
\text { experience }\end{array}$ & + & $\begin{array}{l}\text { Customization } \\
\text { and } \\
\text { personalization } \\
\text { depend on } \\
\text { employee skill } \\
\text { and effort }\end{array}$ & + & $\begin{array}{l}\text { Customization and } \\
\text { personalization can be } \\
\text { delivered on scale at } \\
\text { consistent quality and } \\
\text { performance }\end{array}$ & $\begin{array}{l}\text { The Japanese } \\
\text { considers cleaning } \\
\text { guest rooms as a } \\
\text { human work, while } \\
\text { robots cleans } \\
\text { common facilities } \\
\text { such as corridors and } \\
\text { lobby's [ } 44, \text { p. } 241]\end{array}$ \\
\hline & & + & $\begin{array}{l}\text { Can engage in } \\
\text { deep acting }\end{array}$ & - & $\begin{array}{l}\text { Can engage in surface } \\
\text { acting }\end{array}$ & $\begin{array}{l}\text { The front desk robot's } \\
\text { ability to } \\
\text { communicate is low } \\
\text { or very limited [13, } \\
37,44]\end{array}$ \\
\hline Meso & Markets & + & $\begin{array}{l}\text { Service } \\
\text { employees can be } \\
\text { a source of } \\
\text { competitive } \\
\text { advantage }\end{array}$ & - & $\begin{array}{l}\text { Service robots are } \\
\text { unlikely to be a } \\
\text { source of competitive } \\
\text { advantage }\end{array}$ & $\begin{array}{l}\text { While hotels are } \\
\text { investing in service } \\
\text { robots in the frontline } \\
\text { services, Henn-na, } \\
\text { which opened in } 2015 \\
\text { have replaced many } \\
\text { of its robots by } \\
\text { humans just four } \\
\text { years after opening } \\
\text { [45] }\end{array}$ \\
\hline
\end{tabular}


Table 2. (continued)

\begin{tabular}{|c|c|c|c|c|c|c|}
\hline \multicolumn{2}{|c|}{ Frontline services } & \multicolumn{2}{|c|}{ Employees } & \multicolumn{2}{|c|}{ Robots } & \multirow[b]{2}{*}{\begin{tabular}{|l} 
Henn-na hotel \\
In some western \\
countries cleaning \\
activities are \\
considered a routine \\
and unattractive job
\end{tabular}} \\
\hline Macro & Society & - & $\begin{array}{l}\text { Many service } \\
\text { employees work } \\
\text { in unattractive } \\
\text { jobs }\end{array}$ & + & $\begin{array}{l}\text { Mundane and } \\
\text { unattractive service } \\
\text { jobs can be robot- } \\
\text { delivered }\end{array}$ & \\
\hline & & - & $\begin{array}{l}\text { Important services } \\
\text { are expensive and } \\
\text { scarce if delivered } \\
\text { by service } \\
\text { employees }\end{array}$ & + & $\begin{array}{l}\text { Cost savings of robot- } \\
\text { delivered services will } \\
\text { be competed away, } \\
\text { leading to lower } \\
\text { prices, and increased } \\
\text { consumption and } \\
\text { higher standards of } \\
\text { living }\end{array}$ & $\begin{array}{l}\text { The efficiency of } \\
\text { activities performed } \\
\text { by humans is } \\
\text { measured by the time } \\
\text { needed to execute } \\
\text { them; time spent on } \\
\text { robot labour is less } \\
\text { expensive than paying } \\
\text { humans [44, p. 242]. } \\
\text { In some cases, robots } \\
\text { can reduce the human } \\
\text { workload [46] }\end{array}$ \\
\hline
\end{tabular}

Meso Level: Service robots are unlikely to become an essential source of competitive advantage, at least in the medium to long term [11]. For example, while hotels are investing in frontline robot services, and while there is no consensus in the literature, our view is that humans are still a source of competitive advantage. However, for companies operating in innovative markets that wat to take risks and where the "winners take everything" service robots and advanced AI technologies can become an interesting asset.

Macro Level: At the Henn-na hotel, the efficiency of human activities is measured by the time required to perform them [44] and their relevance to customers. While the nature of hospitality work has created an unparalleled number of part-time jobs, especially seasonal jobs [47], robots are seen as a solution that can help hotels to deal with seasonal employment permanently [12]. Moreover, the time spent working with robots is less expensive than paying to humans [44] and thus more permanent. The above evidence may reinforce social concern about the risk of unemployment caused by robots [48] and/or artificial intelligence [23].

\section{Concluding Remarks}

Although a significant number of hospitality companies are trying to incorporate service robots into their frontline services, only a few have succeeded. The point is that empirical results differ from different service sectors and, despite the academic efforts made so far, there is no consensus in the literature. Therefore, in our view, managers should be very cautious when deciding to integrate service robots into their service 
delivery systems. To the best of our knowledge, in the context of the hospitality industry, frontline services are considered closely related to empathic intelligence, as the integration of service robots has not yet reached the desired stage of service delivery. In a seemingly far-fetched context, organizations will have to decide whether AI will allow the complete replacement of humans by robots capable of performing the required emotional tasks or investing in balanced capacities by integrating robot-human systems. This study contributes to hospitality management by highlighting current frontline service practices, i.e. using service robots and AI technologies; If used well, it can improve future costumer experiences. More research is needed to find appropriate, manageable and replicable solutions to service delivery contexts, especially at the frontline of SDS, where involvement of these service technologies requires complex cognitive and emotional tasks.

\section{References}

1. Engelhardt, K.: Service robotics and artificial intelligence: current research and future directions. ISA Trans. 29(1), 31-40 (1990)

2. Bazzano, F., Lamberti, F.: Human-robot interfaces for interactive receptionist systems and wayfinding applications. Robotics 7(3), 56 (2018)

3. Ramoly, N., Bouzeghoub, A., Finance, B.: A framework for service robots in smart home: an efficient solution for domestic healthcare. IRBM (2018). https://doi.org/10.1016/j.irbm. 2018.10.010

4. Ding, J., Lin, R., Lin, Z.: Service robot system with integration of wearable Myo armband for specialized hand gesture human-computer interfaces for people with disabilities with mobility problems. Comput. Electr. Eng. 69, 815-827 (2018)

5. Chan, A., Tung, V.: Examine the effects of robotic service on brand experience: the moderating role of hotel segment. J. Travel Tourism Mark. 36(4), 458-468 (2019)

6. Choi, S., Liu, S., Mattila, A.: "How may I help you?" Says a robot: examining language styles in the service encounter. Int. J. Hosp. Manag. 82, 32-38 (2019). https://doi.org/10. 1016/j.jhm.2019.03.026

7. Lu, L., Cai, R., Gursoy, D.: Developing and validating a service robot integration willingness scale. Int. J. Hosp. Manag. 80, 36-51 (2019). https://doi.org/10.1016/j.ijhm. 2019.01.005

8. Reis, J., Santo, P., Melão, N.: Impacts of artificial intelligence on public administration: a systematic literature review. In: 14th Iberian Conference on Information Systems and Technologies (CISTI). IEEE (2019)

9. Jarrahi, M.: Artificial intelligence and the future of work: human-AI symbiosis in organizational decision making. Bus. Horiz. 61(4), 577-586 (2018)

10. Joerss, M., Schröder, J., Neuhaus, F., Klink, C., Mann, F.: Parcel Delivery: The Future of Last Mile. McKinsey \& Company (2016)

11. Wirtz, J., et al.: Brave new world: service robots in the frontline. J. Serv. Manag. 29(5), 907931 (2018)

12. Kuo, C., Chen, C., Tseng, C.: Investigating and innovative service with hospitality robots. Int. J. Contemp. Hosp. Manag. 29(5), 1305-1321 (2017)

13. Osawa, H., et al.: Analysis of robot hotel: reconstruction of works with robots. In: International Symposium on Robot and Human Interactive Communication, pp. 219-223. IEEE (2017) 
14. Ivanov, S., Webster, C., Berezina, K.: Adoption of robots and service automation by tourism and hospitality companies. Revista Turismo e Desenvolvimento 27/28, 1501-1517 (2017)

15. Murphy, J., Gretzel, U., Pesonen, J.: Marketing robot services in hospitality and tourism: the role of anthropomorphism. J. Travel Tourism Mark. 36(7), 784-795 (2019). https://doi.org/ 10.1080/10548408.2019.1571983

16. Davis, F.: Perceived usefulness, perceived ease of use, and user acceptance of information technology. MIS Q. 13(3), 318-340 (1989)

17. van Doorn, J., et al.: Domo Arigato Mr. Roboto: emergence of automated social presence in organizational frontlines and customers' service experiences. J. Serv. Res. 20(1), 43-58 (2017)

18. Wünderlich, N., Paluch, S.: A nice and friendly chat with a bot: user perceptions of AI-based service agents. In: Proceedings of the 38th International Conference on Information Systems (2017). https://aisel.aisnet.org/icis2017/ServiceScience/Presentations/11/. Accessed 20 Apr 2019

19. Breazeal, C.: Towards sociable robots. Robot. Auton. Syst. 42(3-4), 167-175 (2003)

20. Nomura, T., Kanda, T.: Rapport-expectation with a robot scale. Int. J. Soc. Robot. 8(1), 2130 (2016)

21. Doney, P., Cannon, J.: An examination of the nature of trust in buyer-seller relationships. J. Mark. 61(2), 35-51 (1997)

22. Lovelock, C.: Classifying services to gain strategic marketing insights. J. Mark. 47(3), 9-20 (1983)

23. Huang, M.-H., Rust, R.: Artificial intelligence in service. J. Serv. Res. 21(2), 155-172 (2018)

24. Saravanan, S., Ramakrishnan, B.: Preserving privacy in the context of location based services through location hider in mobile-tourism. Inf. Technol. Tourism 16(2), 229-248 (2016)

25. Broadbent, E.: Interactions with robots: the truths we reveal about ourselves. Annu. Rev. Psychol. 68, 627-652 (2017)

26. Forman, A., Sriram, V.: The depersonalization of retailing: its impact on the 'lonely' consumer. J. Retail. 67(2), 226-243 (1991)

27. Dyrkolbotn, S.: A typology of liability rules for robot harms. In: Ferreira, M.I.A., Silva Sequeira, J., Tokhi, M.O., Kadar, E.E., Virk, G.S. (eds.) A World with Robots. ISCASE, vol. 84, pp. 119-133. Springer, Cham (2017). https://doi.org/10.1007/978-3-319-46667-5_9

28. Freeman, R.: Who owns the robots rules the world (2015). https://wol.iza.org/articles/whoowns-the-robots-rules-the-world/long. Accessed 20 Apr 2019

29. Reis, J., Amorim, M., Melão, N., Matos, P.: Digital transformation: a literature review and guidelines for future research. In: Rocha, Á., Adeli, H., Reis, L.P., Costanzo, S. (eds.) WorldCIST'18 2018. AISC, vol. 745, pp. 411-421. Springer, Cham (2018). https://doi.org/ 10.1007/978-3-319-77703-0_41

30. Ivanov, S., Webster, C., Garenko, A.: Young Russian adults' attitudes towards the potential use of robots in hotels. Technol. Soc. 55, 24-32 (2018). https://doi.org/10.1016/j.techsoc. 2018.06.004

31. Nakanishi, J., Kuramoto, I., Babam, J., Kohei, O., Yoshikawa, K., Ishiguro, H.: Can a humanoid robot engage in heartwarming interaction service at a hotel? In: Proceedings of the 6th International Conference on Human-Agent Interaction, pp. 45-53. ACM (2018). https:// doi.org/10.1145/3284432.3284448

32. Kaiser, F., Glatte, K., Lauckner, M.: How to make nonhumanoid mobile robots more likable: employing kinesic courtesy cues to promote appreciation. Appl. Ergon. 78, 70-75 (2019). https://doi.org/10.1016/j.apergo.2019.02.004 
33. Wisskirchen, G., et al.: Artificial intelligence and robotics and their impact on the workplace. IBA Global Employment Institute (2017)

34. Rajesh, M.: Inside Japan's first robot-staffed hotel. The Guardian (2015). https://www. theguardian.com/travel/2015/aug/14/japan-henn-na-hotel-staffed-by-robots. Accessed 20 Apr 2019

35. Stock, R., Merkle, M.: A service robot acceptance model: user acceptance of humanoid robots during service encounters. In: IEEE International Conference on Pervasive Computing and Communications Workshops, pp. 339-344. IEEE (2017)

36. Shead, S.: World's first robot hotel fires half of its robots. Forbes (2019). https://www.forbes. com/sites/samshead/2019/01/16/worlds-first-robot-hotel-fires-half-of-its-robots/ \#fc2fe3ce1b1d. Accessed 20 Apr 2019

37. Tung, V., Au, N.: Exploring customer experiences with robotics in hospitality. Int. J. Contemp. Hosp. Manag. 30(7), 2680-2697 (2018)

38. Savela, N., Turja, T., Oksanen, A.: Social acceptance of robots in different occupational fields: a systematic literature review. Int. J. Soc. Robot. 10(4), 493-502 (2018)

39. Pezzullo, J., Tung, G., Rogg, J., Davis, L., Brody, J., Mayo-Smith, W.: Voice recognition dictation: radiologist as transcriptionist. J. Digit. Imaging 21(4), 384-389 (2008)

40. Gartner, D., Kolisch, R., Neill, D., Padman, R.: Machine learning approaches for early DRG classification and resource allocation. Informs J. Comput. 27(4), 718-734 (2015)

41. Reis, J., Amorim, M., Melão, N.: Multichannel service failure and recovery in a $\mathrm{O} 2 \mathrm{O}$ era: a qualitative multi-method research in the banking services industry. Int. J. Prod. Econ. (2018). https://doi.org/10.1016/j.ijpe.2018.07.001

42. Tung, V., Law, R.: The potential for tourism and hospitality experience research in humanrobot interactions. Int. J. Contemp. Hosp. Manag. 29(10), 2498-2513 (2017)

43. Ivanov, S., Gretzel, U., Berezina, K., Sigala, M., Webster, C.: Progress on robotics in hospitality and tourism: a review of the literature. J. Hosp. Tourism Technol. (2019, forthcoming)

44. Osawa, H., et al.: What is real risk and benefit on work with robots? From the analysis of a robot hotel. In: Proceedings of the Companion of the 2017 ACM/IEEE International Conference on Human-Robot Interaction, pp. 241-242. ACM (2017)

45. Gulliver Travels: Why the world's first robot hotel was a disaster. The economist (2019). https://www.economist.com/gulliver/2019/03/27/why-the-worlds-first-robot-hotel-was-adisaster. Accessed 26 Apr 2019

46. Hochschild, A.: The Managed Heart: Commercialization of Human Feeling. University of California Press, Berkeley (2012)

47. Baum, T.: Human Resource Management for Tourism, Hospitality and Leisure: An International Perspective. Thomson, London (2006)

48. Marchant, G.E., et al.: International governance of autonomous military robots. In: Valavanis, K.P., Vachtsevanos, G.J. (eds.) Handbook of Unmanned Aerial Vehicles, pp. 2879-2910. Springer, Dordrecht (2015). https://doi.org/10.1007/978-90-481-9707-1_102 